\title{
FORMAÇÃO ACADÊMICO-PROFISSIONAL DOS DOCENTES FONOAUDIÓLOGOS DO ESTADO DA BAHIA
}

\author{
Academic and professional training of speech \\ and language pathology teachers in the state of Bahia
}

\author{
Vanessa De Nardi (1), Carla Cardoso ${ }^{(2)}$, Roberto Paulo Correia de Araújo (3)
}

\begin{abstract}
RESUMO
Objetivo: analisar a formação do corpo docente graduado em Fonoaudiologia com vistas ao delineamento do perfil acadêmico-profissional do mesmo. Método: estudo observacional, descritivo e analítico, com abordagem quantitativa/ qualitativa, os dados de formação do universo de docentes fonoaudiólogos foram coletados por meio de questionário elaborado para esta finalidade e tratados com base na estatística descritiva. Resultados: a análise mostrou o universo de 62 docentes, distribuídos por quatro IES, majoritariamente do gênero feminino e jovens, tendo realizado a graduação em outros estados, e cuja formação acadêmico-profissional demonstrou ser tecnicista e especializada com prerrogativa dos saberes técnicos pertinentes à profissão. Conclusões: é possível perceber que, apesar de uma formação que em sua maioria não contemplava a área da saúde coletiva, os docentes percebem essa necessidade e procuram, dentro das áreas de atuação, estabelecer alianças com ações preventivas.
\end{abstract}

DESCRITORES: Fonoaudiologia; Educação; Prática Profissional; Saúde Coletiva

\section{INTRODUÇÃO}

A inserção da Fonoaudiologia no Estado da Bahia tem se configurado num aumento do número de profissionais, na instalação de cursos de graduação e, por conseguinte, na oferta de novas opções curriculares. A evolução das Diretrizes Curriculares Nacionais no Brasil, as mudanças mercadológicas no campo do trabalho fonoaudiológico, as demandas de saúde da coletividade e a participação deste profissional no Sistema Único de Saúde têm

(1) Fonoaudióloga; Mestre e Doutoranda pelo Programa de Pós-Graduação em Processos Interativos dos Órgãos e Sistemas - ICS da Universidade Federal da Bahia - UFBA, Salvador, Bahia, Brasil.

(2) Fonoaudióloga; Professora Adjunto do Departamento de Ciências da Vida, curso de Fonoaudiologia; Docente da Universidade do Estado da Bahia - UNEB, Salvador, Bahia, Brasil; Mestre e Doutora em Ciências pela FMUSP.

(3) Odontólogo; Professor Titular de Bioquímica Oral; Livre Docente - ICS da Universidade Federal da Bahia - UFBA; Coordenador do Programa de Pós-Graduação em Processos Interativos dos Órgãos e Sistemas - ICS da Universidade Federal da Bahia - UFBA, Salvador, Bahia, Brasil.

Conflito de interesses: inexistente suscitado profundas reflexões quanto à formação do fonoaudiólogo.

Para tanto, foi realizada uma pesquisa sobre os cursos de graduação em Fonoaudiologia no Estado da Bahia e a formação acadêmico-profissional do corpo docente com vistas a se refletir sobre os projetos pedagógicos e o perfil docente dos profissionais envolvidos na formação de sucessivas gerações para que forneçam subsídios que possam vir a contribuir com a efetiva qualificação da formação profissional, certamente, o que resultará em fonoaudiólogos cujo perfil responderá com maior eficácia às demandas da sociedade, valorizará o exercício profissional interdisciplinar, promoverá a saúde e prevenirá as patologias que possam acometer a coletividade.

Tendo em vista as possíveis mudanças que estão ocorrendo, ainda elementares, no ensino fonoaudiológico, faz-se necessário um docente com atitudes planejadas para a formação de profissionais com perfil generalista, humanista, crítico, reflexivo e que seja capaz de associar os diferentes processos que afetam o ser humano. ${ }^{1-3}$ 
A pesquisa teve como um de seus objetivos analisar a formação do corpo docente graduado em Fonoaudiologia com vistas ao delineamento do perfil acadêmico-profissional do mesmo.

\section{MÉTODO}

A pesquisa tem caráter observacional, descritiva e analítica, com abordagem quantitativa/ qualitativa, por meio do qual foi estudado o universo de 62 docentes fonoaudiólogos, utilizando-se um questionário (Figura 1), aplicado por meio de entrevista presencial, que contemplava perguntas abertas e fechadas que incluem questões genéricas sobre o perfil acadêmico-profissional e perguntas específicas sobre: dados pessoais; formação acadêmica e profissional; exercício profissional; exercício da docência; e função social da Fonoaudiologia.
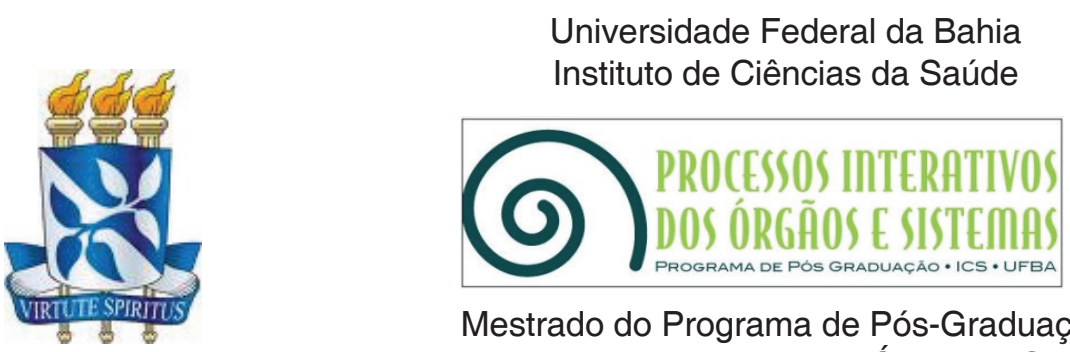

Universidade Federal da Bahia Instituto de Ciências da Saúde

Mestrado do Programa de Pós-Graduação em Processos Interativos dos Órgãos e Sistemas

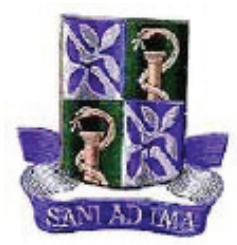
Questionário para os Docentes Fonoaudiólogos
dos Cursos de Graduação em Fonoaudiologia do Estado da Bahia

Nome da Instituição:

Data: / №:

Parte I. Dados Pessoais

1.1- Naturalidade:

1.2 - Se não é natural da Bahia, reside aqui há quanto tempo:

1.3 - Data de Nascimento:

1.4-Gênero: ( ) M ( ) F

Parte II. Formação Acadêmica e Profissional

2.1 - Graduação:

2.1.1 - Nome da Instituição

2.1.2 - Estado:

2.1.3 - Ano de Conclusão:

2.1.4 - Duração do Curso:

2.1.5 - No seu curso de graduação, o currículo vigente contemplava:

( ) Formação Generalista;

( ) Componentes Curriculares Básicos;

( ) Componentes Específicos de cada Subárea Fonoaudiológica;

( ) Enfoque Biopsicossocial, cultural e tecnológico;

( ) Estágios;

( ) Clínica Multidisciplinar/ Co-relação com Outras Áreas;

( ) Atividades Extra-Muros;

( ) Pesquisas;

( ) Incentivo à Pesquisa e a Publicar. 
2.1.6 - Você considera o curso de Graduação que você realizou:
( ) - Péssimo
( ) - Ruim
( ) - Regular
( ) - Bom
( ) - Ótimo

2.1.7 - Há diferenças entre o curso de graduação que você realizou e esse mesmo curso, na atualidade?
( ) - Sim
( ) - Não

2.1.8 - Qual era o tempo de duração da graduação em Fonoaudiologia que cursou?
( ) - Menos que 7 semestres
( ) -7 semestres
( ) -8 semestres
( ) -10 semestres
( ) -9 semestres
( ) - Mais que 10 semestres

2.1.9 - Você considera o tempo de oito semestres de duração um tempo suficiente para o curso de Graduação em Fonoaudiologia?
( ) $-\operatorname{Sim}$
( ) - Não. Quantos semestres deveriam ter o curso?

2.1.10 - Foi sua primeira opção no vestibular?
( ) $-\operatorname{Sim}$
( ) - Não. Qual foi a primeira?

2.2 - Pós-Graduação:

2.2.1 - Você realizou ou está realizando Curso de Pós-graduação?

( ) - Sim

( ) - Não. Indique a razão:

( ) - Falta de tempo;

( ) - Não teve oportunidade;

( ) - É recém-formado;

( ) - Não quis investir, pois não tem interesse;

( ) - Não acredita no retorno financeiro ou profissional.

2.2.2 - Especialização:
( ) - Não
( ) - Sim

( ) - Em Fonoaudiologia. Qual a subárea:

( ) - Linguagem;

( ) - Voz;

( ) - Audição;

( ) - Motricidade Orofacial;

( ) - Saúde Coletiva.

( ) - Em área correlata. Especificar a área:

( )-Cursando ( )-Concluído

2.2.3 - Mestrado:
( ) - Não
( ) $-\operatorname{Sim}$
( ) - Em Fonoaudiologia. Qual a subárea:
( ) - Linguagem;
( ) - Voz;
( ) - Audição;
( ) - Motricidade Orofacial;
( ) - Saúde Coletiva.
( ) - Em área correlata. Especificar a área:
( )-Cursando ( )-Concluído 
2.2.4 - Doutorado:

( ) - Não ( ) - Sim

( ) - Em Fonoaudiologia. Qual a subárea:

( ) - Linguagem;

( ) - Voz;

( ) - Audição;

( ) - Motricidade Orofacial;

( ) - Saúde Coletiva.

( ) - Em área correlata. Especificar a área:

( ) -Cursando ( )-Concluído

2.2.5 - Outro:
( ) - Não
( ) - Sim. Especificar:

2.3 - Formação continuada:

2.3.1 - Participou de cursos de Atualização com carga horária maior que 80h?
( ) - Não
( ) - Sim. Qual especialidade (s):

2.3.2 - Participou de Congressos, Jornadas e Simpósios nos últimos anos?
( ) - Não
( ) - Sim. Quantos?

2.3.3 - Já participou de alguma Atividade Científica Internacional?
( ) - Não
( ) - Sim. Quantas?

2.3.4 - Lê com freqüência alguma Publicação Periódica Científica?
( ) - Não
( ) - Sim. Quantas por mês?

2.3.5 - Acha indispensável fazer Mestrado e (ou) Doutorado?
( ) - Sim
( ) - Não. Por quê?

Parte III. Exercício Profissional

3.1 - Exercício Profissional. Trabalha:

3.1.1 - Em Clínica Particular?
( ) $-\operatorname{Sim}$
( ) - Não

3.1.2 - Em Consultório Próprio?
( ) $-\mathrm{Sim}$
( ) - Não

3.1.3 - Com Assistência Domiciliar ou Home Care?
( ) - Sim
( ) - Não

3.1.4 - Com Fonoaudiologia Ocupacional?
( ) - Sim
( ) - Não

3.1.5 - Em Asilos e Casas de Saúde?
( ) - Sim
( ) - Não

3.1.6 - Escolas Regulares e Especiais?
( ) - Sim
( ) - Não

3.1.7 - Em Creches e Berçários?
( ) $-\mathrm{Sim}$
( ) - Não 
3.1.8 - Hospitais?
( ) - Não
( ) - Sim. Quais setores em que atua?

3.1.9 - Maternidades?
( ) - Não
( ) - Sim. Quais setores em que atua?

3.1.10 - Em Empresas?
( ) - Sim
( ) - Não

3.1.11 - Empresas de Telemarketing?
( ) $-\operatorname{Sim}$
( ) - Não

3.1.12 - Meios de Comunicação?
( ) $-\operatorname{Sim}$
( ) - Não

3.1.13 - Com Projetos Assistenciais Filantrópicos?
( ) - Sim
( ) - Não

3.1.14 - Unidades Básicas de Saúde?
( ) - Sim
( ) - Não

3.1.15 - Ambulatórios de Especialidades?
( ) - Sim
( ) - Não

3.1.16 - Pesquisas Científicas?
( ) - Sim
( ) - Não

3.1.17 - Projetos Fonoaudiológico-educacionais?
( ) - Sim
( ) - Não

3.1.18 - Em Instituições de Ensino Superior?
( ) $-\operatorname{Sim}$
( ) - Não

3.1.19 - Diretamente com Programa do Governo Federal NASF, SUS e ESF?
( ) $-\operatorname{Sim}$
( ) - Não

3.1.20 - Em outro local?
( ) - Não
( ) - Sim. Local:

3.2 - Situação Profissional:

3.2.1 - Enquadramento Profissional:
( ) - Autônomo
( ) - Servidor Público
( ) - Sim ( ) - Não
( ) - Não ( ) - Sim. Qual?
( ) - Municipal;
( ) - Estadual;
( ) - Federal.
( ) - Prestador de Serviços
( ) - Não
( ) - Sim. Qual?
( ) - Instituição Privada
( ) - Iniciativa Privada
( ) - Instituição Pública

$$
\text { ( ) - Sim ( ) - Não }
$$


3.2.2 - Jornada de Trabalho Total semanal:
( ) - Menos que 10h;
( ) $-10 \mathrm{~h}$;
( ) $-20 \mathrm{~h}$;
( ) $-30 \mathrm{~h}$;
( ) $-40 \mathrm{~h}$;
( ) - Mais que 40h.

3.2.3 - Participação em Entidades de Classe:

( ) - Vinculadas à Fonoaudiologia. Indicar:

( ) - Não vinculadas à Fonoaudiologia. Indicar:

3.3 - Pratica Ações de Caráter:

3.3.1 - Educativo-preventivo individualmente?
( ) - Não
( ) - Sim. Onde?

3.3.2 - Educativo-preventivo coletivamente?
( ) - Não
( ) - Sim. Onde?

3.4 - Está realizado (a) profissionalmente?
( ) - Sim
( ) - Não. Por quê?

3.5 - Estimula a valorização da Fonoaudiologia para a sociedade?

( ) - Sim ( ) - Não. Por quê?

Parte IV. Exercício da Docência

4.1 - Relação Empregatícia com a Instituição em que leciona:

4.1.1.A - Instituição:

( ) - Pública. Qual

( ) - Privada. Qual

4.1.2.A - Horas/ aula semanais:

( ) - Tempo Parcial (20h semanais)

$\mathrm{n}^{\circ}$ de h/aulas em sala:

$\mathrm{n}^{\circ}$ de $\mathrm{h} /$ aulas em pesquisa:

( ) - Tempo Integral (40h semanais)

$\mathrm{n}^{\circ}$ de $\mathrm{h} / \mathrm{aulas}$ em sala:

$n^{\circ}$ de h/aulas em pesquisa:

( ) - Dedicação Exclusiva

$\mathrm{n}^{\circ}$ de h/aulas em sala:

$\mathrm{n}^{\circ}$ de $\mathrm{h} /$ aulas em pesquisa:

4.1.3.A - Situação na carreira:
( ) - Titular
( ) - Assistente
( ) - Adjunto
( ) - Auxiliar
( ) - Substituto ( ) - Prof.Ens. Sup.
( ) - Outra. Indicar:

4.1.4.A - Tempo em que atua na Instituição:

( ) -30 a 21 anos.

( ) -20 a 11 anos.

( ) -10 a 1 ano.

( ) - Menos 1 ano.
4.1.1.B - Instituição:

( ) - Pública. Qual

( ) - Privada. Qual

4.1.2.B - Horas/ aula semanais:

( ) - Tempo Parcial (20h semanais)

$\mathrm{n}^{\circ}$ de h/aulas em sala:

$\mathrm{n}^{\circ}$ de $\mathrm{h} /$ aulas em pesquisa:

( ) - Tempo Integral (40h semanais)

$n^{\circ}$ de h/aulas em sala:

$\mathrm{n}^{\circ}$ de h/aulas em pesquisa:

( ) - Dedicação Exclusiva

$\mathrm{n}^{\circ}$ de h/aulas em sala:

$\mathrm{n}^{\circ}$ de $\mathrm{h} /$ aulas em pesquisa:

4.1.3.B - Situação na carreira:
( ) - Titular
( ) - Assistente
( ) - Adjunto
( ) - Auxiliar
( ) - Substituto ( )-Prof.Ens. Sup.
( ) - Outra. Indicar:

4.1.4.B - Tempo em que atua na Instituição:
( ) -30 a 21 anos
( ) -20 a 11 anos.
( ) -10 a 1 ano.
( ) - Menos 1 ano. 
4.1.5.A - Aulas que Ministra/ Componentes Curriculares? Teórica?( ) - Não ( ) - Sim. Quais?

Prática?( ) - Não ( ) - Sim. Quais?

4.1.6.A - Exerce outra Função na Instituição?

( ) - Não ( ) - Sim. Quais?

4.1.1.C - Instituição:

( ) - Pública. Qual

( ) - Privada. Qual

4.1.2.C - Horas/ aula semanais:

( ) - Tempo Parcial (20h semanais)

$\mathrm{n}^{\circ}$ de $\mathrm{h} /$ aulas em sala:

$n^{\circ}$ de h/aulas em pesquisa:

( ) - Tempo Integral (40h semanais)

$\mathrm{n}^{\circ}$ de $\mathrm{h} / \mathrm{aulas}$ em sala:

$n^{\circ}$ de h/aulas em pesquisa:

( ) - Dedicação Exclusiva

$\mathrm{n}^{\circ}$ de h/aulas em sala:

$\mathrm{n}^{\circ}$ de $\mathrm{h} /$ aulas em pesquisa:

4.1.3.C - Situação na carreira:
( ) - Titular
( ) - Assistente
( ) - Adjunto
( ) - Auxiliar
( ) -Substituto ( ) - Prof. de Ens. Sup.
( ) - Outra. Indicar:

4.1.4.C - Tempo em que atua na Instituição:

( ) -30 a 21 anos

( ) -20 a 11 anos.

( ) -10 a 1 ano.

( ) - Menos 1 ano.

4.1.5.C - Aulas que Ministra/ Componentes Curriculares?

Teórica?( ) - Não ( ) - Sim. Quais?

Prática?( ) - Não ( ) - Sim. Quais?

4.1.6.C - Exerce outra Função

( ) - Não ( ) - Sim. Quais?
4.1.5.B - Aulas que Ministra? Componentes Curriculares

Teórica?( ) - Não ( ) - Sim. Quais?

Prática?( ) - Não ( ) - Sim. Quais?

4.1.6.B - Exerce outra Função na Instituição?

( ) - Não ( ) - Sim. Quais?

4.1.1.D - Instituição:

( ) - Pública. Qual

( ) - Privada. Qual

4.1.2.D - Horas/ aula semanais:

( ) - Tempo Parcial (20h semanais)

$\mathrm{n}^{\circ}$ de $\mathrm{h} / \mathrm{aulas}$ em sala:

$\mathrm{n}^{\circ}$ de $\mathrm{h} /$ aulas em pesquisa:

( ) - Tempo Integral (40h semanais)

$\mathrm{n}^{\circ}$ de $\mathrm{h} / \mathrm{aulas}$ em sala:

$n^{\circ}$ de $h / a u l a s$ em pesquisa:

( ) - Dedicação Exclusiva

$n^{\circ}$ de h/aulas em sala:

$\mathrm{n}^{\circ}$ de $\mathrm{h} /$ aulas em pesquisa:

4.1.3.D - Situação na carreira:

( ) - Titular ( )-Assistente ( )-Adjunto ( )-Auxiliar

( ) - Substituto ( ) - Prof. Ens. Sup.

( ) - Outra. Indicar:

4.1.4.D - Tempo em que atua na Instituição:

( ) -30 a 21 anos.

( ) -20 a 11 anos.

( ) -10 a 1 ano.

( ) - Menos 1 ano.

4.1.5.D - Aulas que Ministra/ Componentes Curriculares?

Teórica?( ) - Não ( ) - Sim. Quais?

Prática?( ) - Não ( ) - Sim. Quais?

4.1.6. D- Exerce outra na Instituição?
( ) - Não
( ) - Sim. Quais?

4.2 - É docente em outra Instituição?
( ) - Não
( ) - Sim 
4.3 - Tempo total de serviço como docente: Indicar:

4.4 - Opção pelo exercício da docência foi?

( ) - Premeditado ( ) - Casual

4.5 - Você adquiriu alguma formação pedagógica para o exercício da docência?
( ) - Não
( ) - Sim. Qual?

4.5.1 - Sua formação pedagógica foi por iniciativa própria?
( ) - Sim
( ) - Não

4.5.2 - Seu treinamento pedagógico é:
( ) - Freqüente
( ) - Esporádico

4.6 - Estimula o discente a pesquisar, a buscar o conhecimento científico?
( ) - Sim
( ) - Não

4.7 - Você incentiva o discente quando ele apresenta dúvidas com relação à profissão escolhida?
( ) $-\operatorname{Sim}$
( ) - Não

Parte V. Função Social da Fonoaudiologia

5.1 - Você acredita que o desenvolvimento de ações educativas é capaz de reduzir a incidência de alterações fonoaudiológicas?
( ) $-\operatorname{Sim}$
( ) - Não

5.2 - Como docente de graduação, você debate as condições de inserção do fonoaudiólogo no PSF e no SUS?
( ) $-\operatorname{Sim}$
( ) - Não

5.3 - Você acha adequada e suficiente as Diretrizes Nacionais Curriculares para os Cursos de Fonoaudiologia e o Processo de Reforma Curricular?
( ) - Sim
( ) - Não

5.4 - Você acredita que os conteúdos abordados e procedimentos metodológicos desenvolvidos em sala de aula são suficientes para a formação de um fonoaudiólogo?
( ) $-\operatorname{Sim}$
( ) - Não

5.5 - A carga horária de sua disciplina e os recursos disponíveis para o desenvolvimento são satisfatórios?
( ) - Sim
( ) - Não

5.6 - Você considera importante, na formação, o contato dos alunos com o SUS e com outros espaços de atendimento comunitário?
( ) - Sim
( ) - Não

5.7 - Você acredita ser importante focalizar o aspecto preventivo e de promoção da saúde em todas as unidades curriculares?
( ) $-\operatorname{Sim}$
( ) - Não

Figura 1 - Questionário para os Docentes Fonoaudiólogos dos Cursos de Graduação em Fonoaudiologia do Estado da Bahia 
A pesquisa foi realizada com 0 intuito de abranger todo o Estado da Bahia, porém as instituições de ensino superior estão localizadas na capital Salvador (3 IES) e na região metropolitana (1 IES), durante o ano de 2010.

Esta pesquisa foi aprovada pelo Comitê de Ética em Pesquisa da Faculdade de Odontologia da Universidade Federal da Bahia sob o número: FR: 267362 CAAE: 0027.0.368.368-09.

Concluída a coleta de dados, as perguntas foram classificadas e agrupadas, de acordo com as variáveis e os construtos que se desejava estudar, as respostas foram tabuladas e apresentadas de forma estruturada para análise estatística no programa SPSS Statistics 17.0. Os dados obtidos foram confrontados sempre que possível, com o intuito de assegurar as correlações possíveis e sua consistência. Foram aplicados os recursos da estatística descritiva simples (porcentagens e cálculos simples). A pesquisa de campo foi o delineamento adotado, pois esta integra diferentes abordagens e técnicas, tanto qualitativas quanto quantitativas.

\section{RESULTADOS}

A análise das quatro Instituições de Ensino Superior - IES que mantêm o curso de graduação em Fonoaudiologia em funcionamento no estado da Bahia revela que a distribuição dos docentes fonoaudiólogos que ministram disciplinas nos cursos de Fonoaudiologia possui um universo de 62 docentes com graduação em Fonoaudiologia, indica que a Universidade Federal da Bahia - UFBA, instituição pública mantida pelo Governo, detém 20 docentes do universo, seguida da Universidade do Estado da Bahia - UNEB, também mantida pelo governo, e da União Metropolitana de Educação e Cultura UNIME, instituição particular, com e 15 docentes cada uma, enquanto que o Centro Universitário Jorge Amado - UNIJORGE, também particular, possui 12 docentes do universo.

Vários docentes exercem a docência em mais de uma IES, sendo que a UFBA compartilha dois profissionais com a UNIJORGE e possui 18 profissionais exclusivos. A UNEB possui sete docentes exclusivos no seu quadro funcional, sete profissionais compartilhados com a UNIME e um docente compartilhado com outras duas instituições UNIME e UNIJORGE. A UNIJORGE possui oito docentes exclusivos, um docente compartilhado com outras duas IES, UNIME e UNEB, três docentes compartilhados com outra instituição, sendo dois docentes com a UFBA e um docente compartilhado com a UNIME. Na sequência, a UNIME possui sete docentes exclusivos, sete docentes compartilhados com outra instituição, sendo seis profissionais compartilhados com a UNEB, um docente compartilhado com a UNIJORGE, e um docente compartilhado com outras duas IES - a UNIJORGE e a UNEB.

Do universo de 62 docentes, 60 são do gênero feminino e dois do gênero masculino.

Tabela $1-$ Naturalidade dos docentes
fonoaudiólogos vinculados às quatro IES do
Estado da Bahia - Salvador (2010)

\begin{tabular}{lc}
\hline Naturalidade & Docentes \\
\hline São Paulo & 24 \\
Bahia & 15 \\
Pernambuco & 6 \\
Rio Grande do Sul & 4 \\
Minas Gerais & 3 \\
Distrito Federal & 3 \\
Paraná & 3 \\
Ceará & 2 \\
Alagoas & 1 \\
Rio de Janeiro & 1 \\
\hline Total & 62 \\
\hline
\end{tabular}

Os docentes que são naturais de outros estados residem no estado da Bahia em torno de 13,6 anos, sendo que o docente com domicílio neste estado há mais tempo está há 31 anos e o que reside há menos tempo está há três meses.

A faixa etária de nascimento com maior número de docentes fonoaudiólogos é a de 1976-1980 com 15 profissionais, seguida pelas faixas de 19661970 e 1971-1975, cada uma com 12 profissionais cada, na sequência 1981-1985 com 11 docentes, 1961-1965 com sete profissionais, 1960-1955 com quatro docentes, enquanto que um docente não respondeu. O mais jovem possui 26 anos e o mais velho 55 anos, com uma média de idade é de 37,3 anos, caracterizando uma população jovem de docentes.

A graduação em fonoaudiologia desses profissionais foi realizada em uma das 21 IES, distribuídas em nove estados federativos. Sendo que 29 docentes se graduaram no estado de São Paulo, 12 docentes no estado da Bahia, sete no estado de Pernambuco, quatro no estado do Ceará, três no Rio Grande do Sul, três no Paraná, dois no Rio de Janeiro, um no estado de Alagoas e um em Minas Gerais.

Dos 12 docentes que se graduaram nas três IES situadas no estado da Bahia, cinco são graduados pela Universidade Federal da Bahia, cinco 
pela Universidade do Estado da Bahia e dois se graduaram pela União Metropolitana de Educação e Cultura. Dos 29 docentes se graduaram no estado de São Paulo em nove diferentes IES, sete se graduaram na Pontifícia Universidade Católica de São Paulo, cinco se graduaram na Universidade São Paulo, quatro na Universidade do Estado de São Paulo, quatro na Universidade Federal do Estado de São Paulo, dois na Pontifícia Universidade Católica de Campinas, dois na Universidade de São Paulo, campus Bauru, dois na Universidade Sagrado Coração, um no Centro Universitário São Camilo e um último nas Faculdades Integradas Teresa D'Avila. Dos sete docentes que se graduaram em Pernambuco, todos cursaram a Universidade Católica de Pernambuco. Os quatro que se graduaram no estado do Ceará, cursaram a Universidade de Fortaleza. Os três docentes que se graduaram no Rio Grande do Sul, realizaram seu curso na Universidade Federal de Santa Maria. No Paraná, três docentes cursaram a Pontifícia Universidade Católica do Paraná. Dos dois docentes que se graduaram no Rio de Janeiro, um cursou a Pontifícia Universidade Católica de Petrópolis e um cursou o Centro Universitário de Barra Mansa. $\mathrm{O}$ docente que se graduou em Alagoas, cursou a Universidade Estadual de Ciências da Saúde de Alagoas. E o docente que se graduou em Minas Gerais cursou a Faculdades Metodistas Integradas Isabela Hendrix. Mostra-se que 34 dos docentes realizaram sua graduação em IES públicas e 28 docentes em IES privada.

Do universo de 62 docentes fonoaudiólogos, 49 docentes cursaram sua graduação em seu estado federativo de origem e 13 docentes obtiveram sua graduação em outro estado federativo. Sendo que dos 15 docentes baianos, dez realizaram sua graduação no próprio estado, quatro no estado de São Paulo e um no Rio de Janeiro. Os seis docentes pernambucanos graduaram-se em seu próprio estado, assim como os três docentes paranaenses, o único docente alagoano e o único carioca. Dos 24 docentes paulistas, 23 se graduaram em São Paulo e um na Bahia. Dos quatro docentes gaúchos, três se graduaram em seu próprio estado e um em São Paulo. Entre os três mineiros, um graduou-se em seu estado, um em São Paulo e outro na Bahia. Já os três docentes que são originários do Distrito Federal se graduaram no Ceará.

O ano de conclusão do curso de graduação em fonoaudiologia foi agrupado em faixas com intervalo de cinco anos, sendo a faixa de 1996-2000 a que contém o maior número de docentes, equivalendo a 18 pessoas, seguida da faixa de 1986-1990 com 16 docentes; na sequência, vem as faixas de 2001 2005 com dez docentes, de 1991-1995 a que elenca oito docentes, a de 2006-2010 com sete docentes e a de 1976-1980 com três docentes. A faixa de 1981-1985 não contemplou profissional algum. O ano de conclusão da graduação mais remoto foi 1977 , e o mais recente foi 2008 . O profissional mais experiente tem 33 anos de formado, e a concentração maior é de um tempo médio de formação de menos de 20 anos.

O tempo de duração da graduação em fonoaudiologia com maior número de pessoas foi o de oito semestres com 45 docentes, na sequência foi o de nove semestres com 12 docentes, seguida por seis semestres e dez semestres com um docente cada, três docentes não responderam a questão.

Foram, também, questionados quanto ao conteúdo curricular que a graduação que cursaram contemplava.

Tabela 2 - Variáveis contempladas pelos cursos de graduação de docentes fonoaudiólogos Salvador (2010)

\begin{tabular}{lc}
\hline Variáveis & Docentes $\mathbf{~} \mathbf{~ = 6 2}$ \\
\hline Formação generalista & 45 \\
$\begin{array}{l}\text { Componentes curriculares } \\
\text { básicos }\end{array}$ & 52 \\
$\begin{array}{l}\text { Componentes curriculares } \\
\text { específicos }\end{array}$ & 44 \\
$\begin{array}{l}\text { Enfoque biopsicossocial, } \\
\text { cultural, tecnológico }\end{array}$ & 32 \\
Presença de estágios & 59 \\
$\begin{array}{l}\text { Clínica multidisciplinar, contato } \\
\text { comáreas correlatas }\end{array}$ & 36 \\
$\begin{array}{l}\text { Atividades extramuros } \\
\text { Pesquisas } \\
\text { Incentivo a pesquisar e a } \\
\text { publicar }\end{array}$ & 38 \\
\hline
\end{tabular}

Do universo de 62 docentes fonoaudiólogos, responderam ao questionamento de acordo com o que conhecem atualmente sobre os demais cursos de graduação em fonoaudiologia, as diretrizes curriculares e o SUS. Contata-se que nenhum docente fonoaudiólogo obteve uma formação integral.

Em sua graduação, 28 docentes afirmaram que a qualidade de seu curso como ótimo, 27 docentes colocaram como bom, cinco profissionais como regular e dois docentes com a qualidade ruim.

Dentre eles, 53 afirmaram que existem diferenças entre o curso em que se graduou e atualmente, um docente negou, pois este concluiu o curso em 2008 e oito docentes não responderam, 
muitos não sabiam informar ou o curso foi extinto ou suspenso.

Os 45 optaram pelo curso de fonoaudiologia com primeira opção no vestibular, um docente não respondeu a pergunta e 16 docentes colocaram com segunda opção, destes 16 profissionais, nove docentes optaram por medicina, dois docentes colocaram odontologia, dois profissionais por psicologia, dois docentes em jornalismo e um docente optou por fisioterapia.

Os 52 docentes afirmaram que estão realizados profissionalmente e dez docentes não estão realizados profissionalmente. O universo de docentes afirmam que estimulam a valorização da profissão fonoaudiologia. Sendo que 60 docentes estimulam o discente a pesquisar e a buscar o conhecimento científico, dois docentes não responderam a pergunta. E 57 docentes incentivam os discentes, quando estes apresentam dúvidas com relação à profissão escolhida.

O universo de docentes fonoaudiólogos afirmam que possui pós-graduação. Sendo que 57 docentes possuem especialização, 48 docentes fizeram mestrado e 13 docentes doutorado.

Do universo de 62 docentes, 46 docentes realizaram cursos de atualização em fonoaudiologia, sendo que 13 docentes realizaram em motricidade orofacial, nove docentes fizeram em voz, oito docentes em linguagem, oito docentes em audiologia, seis docentes não informaram a área e dois docentes realizaram em saúde coletiva.

Da população de 57 docentes fonoaudiólogos que realizaram especialização, 16 docentes fizeram em audiologia, 13 docentes se especializaram em linguagem, nove em voz, sete em motricidade orofacial, dois em área correlata, dois em linguagem e voz, dois em linguagem e audiologia, um não informou a área, um realizou em saúde coletiva, um em saúde coletiva e voz, um em voz e motricidade orofacial, um em linguagem e motricidade orofacial, um fez linguagem, motricidade orofacial e audiologia.

Dos 48 docentes fonoaudiólogos que fizeram mestrado, 14 docentes fizeram em área correlata, 12 docentes realizaram na área de linguagem, dez docentes fizeram em voz, dez profissionais em audição, quatro docentes obtiveram o mestrado em saúde coletiva, um docente fez em motricidade orofacial, um em linguagem e motricidade orofacial e três docentes não informaram a área.

Com relação ao doutorado apenas 13 docentes possuem esse nível de pós-graduação, sendo que nove docentes cursaram e quatro docentes estão cursando, todos em área correlata.

Do universo de docentes fonoaudiólogos, 54 docentes afirmam que é indispensável realizar mestrado e doutorado, quatro docentes não responderam e quatro docentes acham dispensável a realização de mestrado e doutorado.

Tabela 3 - Exercício profissional de docentes fonoaudiólogos - Salvador (2010)

\begin{tabular}{lc}
\hline Variáveis & Docentes \\
\hline Clínica particular & 28 \\
Consultório próprio & 22 \\
Assistência domiciliar & 11 \\
Fonoaudiologia ocupacional & 7 \\
Asilos / casas de repouso & 4 \\
Escolas & 6 \\
Creches & - \\
Hospitais & 23 \\
Maternidades & 6 \\
Empresas & 5 \\
Telemarketing & 2 \\
Meios de comunicação & 3 \\
Filantropia & 10 \\
UBS & 8 \\
Ambulatório & 19 \\
Pesquisa científica & 51 \\
Projetos educacionais & 21 \\
SUS, NASF, ESF & 13 \\
\hline
\end{tabular}

No enquadramento profissional 27 docentes se declararam autônomos, 13 docentes não são e 22 não responderam. São servidores públicos 46 docentes, sendo que um é servidor municipal, 27 são servidores estaduais e 18 são servidores federais, oito não são servidores e oito não responderam. São prestadores de serviço 21, sendo que 16 prestam serviços no setor privado e cinco no setor público, 20 docentes não são prestadores de serviço e 21 docentes não responderam. Quanto à iniciativa privada 29 trabalham nela, 15 não e 18 não responderam.

Dos 62 docentes, 36 afirmaram que sua jornada de trabalho total semanal é maior que 40 horas, 22 colocaram 40 horas, dois colocaram como resposta 30 horas e dois responderam 20 horas semanais.

A relação empregatícia conforme o regime de tempo de trabalho revela que 29 docentes atuam em tempo parcial de 20 horas, 22 trabalham em tempo integral de 40 horas, dez atuam em regime de dedicação exclusiva de 40 horas e um não respondeu a questão. Todos os dez docentes que atuam em regime de dedicação exclusiva são da UFBA, também nesta IES, seis atuam em regime de 
tempo parcial de 20 horas e são professores substitutos assim como os outros quatro docentes que atuam em regime de tempo integral de 40 horas. $\mathrm{Na}$ UNEB, um docente atua em regime de tempo parcial e os outros 14 atuam em regime de tempo integral. $\mathrm{Na}$ UNIME, um docente não respondeu a questão, 12 atuam em regime de tempo parcial e um atua em regime de tempo integral. E na UNIJORGE, dois docentes trabalham em regime de tempo integral e dez atuam em regime de tempo parcial.

A situação na carreira dos docentes fonoaudiólogos é a de que na UNEB, um docente é professor titular, um é adjunto, um é substituto, quatro são assistentes e oito são auxiliares, na UFBA, dez docentes são substitutos, cinco são adjuntos e cinco são assistentes, na UNIME, um docente não respondeu a pergunta, nove são professores de ensino superior e dois são horistas e na UNIJORGE, dois docentes são horistas e dez são professores de ensino superior.

Do universo, 24 docentes possuem formação pedagógica para atuar, 40 afirmaram que foi por iniciativa própria e que o treinamento pedagógico é frequente para 15 e esporádico para 36 docentes. Dos 24 docentes que obteve formação pedagógica, dois não informaram qual formação, dez obtiveram por meio do mestrado, nove pela de especialização e três pela graduação.

Do universo de docentes, 21 concordaram que as diretrizes curriculares para os cursos de graduação em Fonoaudiologia são adequadas e suficientes, juntamente com o processo de reforma curricular; nove não responderam o questionamento; 32 não concordam com as Diretrizes Curriculares Nacionais.

Os conteúdos abordados e os procedimentos metodológicos desenvolvidos no curso foram considerados suficientes para a formação do fonoaudiólogo segundo 41 docentes fonoaudiólogos, enquanto 21 não os consideram suficientes.

Trinta docentes fonoaudiólogos consideraram que a carga horária das disciplinas que ministram e os recursos utilizados são satisfatórios; 28 não consideraram satisfatórios; quatro docentes não responderam a pergunta. Muitos frisaram que não consideram satisfatórios os recursos utilizados por considerar baixa a carga horária atribuída às disciplinas.

Quanto a estimular o discente a pesquisar e a buscar o conhecimento científico, 60 docentes fonoaudiólogos declararam que assim o fazem; dois docentes não responderam a pergunta. Como 51 dos 62 desses docentes afirmaram que trabaIham com pesquisas científicas.
Diante da dúvida dos discentes em relação à profissão escolhida, 57 docentes fonoaudiólogos declararam que os auxiliam nessa dificuldade.

A totalidade dos docentes fonoaudiólogos concorda que o desenvolvimento de ações educativas é capaz de reduzir a incidência de alterações fonoaudiológicas. Também 0 universo desses docentes entende que é importante focalizar o aspecto preventivo em todas as unidades curriculares e concorda que os discentes devem ter contato com o SUS e outros espaços de atendimento comunitário. Além disso, 49 docentes debatem com os discentes as condições de inserção do fonoaudiólogo no PSF e no SUS; 12 docentes não abordaram esse tema; um docente não respondeu a pergunta.

Quanto à prática de ações preventivo-educativas no exercício profissional pelos docentes fonoaudiólogos, 25 realizam essas ações individualmente: dez em consultório; oito em IES; três em escolas; três em UBS; um em hospital. Por outro lado, 31 docentes as exercem coletivamente: 14 em IES; sete em escolas; quatro em UBS; três em consultório; dois em hospitais; um em ONG.

\section{DISCUSSÃO}

O processo de aprendizagem deve ocorrer por meio da dialética entre educador e educando, possibilitando a ambos um processo de emancipação. O trabalho de construção do conhecimento é realizado pelas vivências de experiências significativas. Nesse processo, é importante que o educador sirva como um mobilizador para a aquisição de novos conhecimentos, partindo dos conhecimentos previamente necessários. Sendo assim, o docente deve ter a competência prática, cientifica e didático-pedagógica, estando bem preparado para o trabalho interdisciplinar que possibilitará que esse processo seja integral. ${ }^{4-8}$

$\mathrm{Na}$ educação continuada que se trás temas universais e nacionais, valorizando a cultura regional e local com suas expressões e seus códigos, com uma educação voltada à prática, considerando os aspectos teóricos que fundamentam os diversos conteúdos. ${ }^{9-11}$

O distanciamento entre a formação acadêmica e o da real prestação de serviços de saúde tem sido um dos responsáveis pela crise mundial do setor da saúde. ${ }^{12}$ Uma das funções prioritárias do Ministério da Saúde é a de ordenar a formação de recursos humanos para a área de saúde. Porém, este se defronta com a precária disponibilidade de profissionais com formação generalista, dotados de uma visão humanística e preparados para prestar cuidados contínuos e resolutivos à comunidade, sendo que o profissional deve estar atento 
ao acelerado ritmo de evolução do conhecimento, à mudança do processo do trabalho em saúde, às transformações nos aspectos demográficos e epidemiológicos, tendo como perspectiva o equilíbrio entre a excelência técnica e a relevância social. Até o ano de 2002, quando foi publicada as LDB para a Fonoaudiologia, era preconizado a formação e um egresso altamente clínico e tecnicista. 8,13

Essa migração de profissionais oriundos das regiões sul, sudeste e do estado de Pernambuco, deve-se principalmente a origem profissional ligada à criação e formação da fonoaudiologia enquanto profissão e ciência, a tradição e a alta incidência de profissionais, pois nesses lugares existem profissionais formados desde as décadas de 1950 e 1960.

Em pesquisa semelhante realizada com cirurgiões-dentistas docentes no Estado da Bahia, também foi constatado um maior contingente de profissionais do gênero feminino com 120 docentes, frente ao gênero masculino com 84 docentes do total de 204 docentes da amostra. ${ }^{14}$

É relatado que com exceção dos cursos de medicina e educação física, as mulheres são a maioria nos cursos da área de saúde. ${ }^{15}$ Há um processo de feminilização nas profissões da área da saúde, aumentando a participação do trabalho feminino, optando por profissões liberais e autônomas, com uma maior flexibilidade de horários e o que também, condiz com o histórico da Fonoaudiologia. ${ }^{16}$

Como a graduação em Fonoaudiologia no estado da Bahia apenas teve início em 1999 e com a primeira turma colando grau em 2003, em decorrência da demanda profissional, houve a migração de profissionais de outros estados e do Distrito Federal para a Bahia e da busca pelos baianos pela graduação em fonoaudiologia em outros estados do Brasil. ${ }^{17}$

Nota-se que a região sudeste representada aqui pelos estados de São Paulo, Rio de Janeiro e Minas Gerais, compreendem a maioria da graduação em fonoaudiologia dos docentes vinculados às IES baianas foco do estudo, devendo acrescentar que é na região supracitada que houve um maior desenvolvimento da profissão e da docência e que agora, certamente, pode estar gerando uma saturação em seu mercado de trabalho, levando a uma busca pelos profissionais de campos de trabalho em outros estados da federação. Sendo o exercício da docência parece ser o principal elemento responsável pela migração de profissionais dos demais estados brasileiros em que se graduaram para 0 estado da Bahia.

Constata-se que nenhum docente fonoaudiólogo obteve uma formação integral. Os resultados revelam que, embora o questionamento sobre as variáveis que seu curso de graduação em fonoaudiologia contemplava não obteve o universo de respostas em nenhuma variável, nota-se que para 55 docentes o seu curso de graduação possuía uma qualidade que variava entre boa e ótima, constatando que mesmo com a escassez de algumas variáveis eles não consideraram isso e sim o curso pelo todo.

A formação na área de saúde e como consequência em Fonoaudiologia mostra que um dinamismo e um acelerado ritmo de evolução do conhecimento requerem mudanças contínuas e atuantes nas diversas estruturas da formação, como a IES, coordenação, corpo docente, projeto pedagógico e currículo. ${ }^{12}$ Nas IES baianas, atualmente, estão ocorrendo modificações estruturais, nos projetos e currículos e capacitações do corpo docente, como por exemplo, oficinas, sensibilização docente, afim de que se adéquem às novas DCN.

A maior opção no vestibular é pela graduação em Medicina, sendo o concurso vestibular mais concorrido da área de saúde, o que relega mais uma vez a Fonoaudiologia como segunda opção entre várias, parece depender da propaganda institucional e da demanda de mercado, porém muitas vezes passa pelo desconhecimento. ${ }^{15,18,19}$ Independentemente da escolha no vestibular sobre o curso de graduação em Fonoaudiologia ter sido primeira ou segunda opção, apesar de ser minoritária a pulverização de escolhas por outras profissões, ainda assim a área preferencial foi a de saúde.

É por meio da educação que abrange os processos formativos que compõem e cercam o ser, que as ações fonoaudiológicas deverão vincular-se à prática social.

Ainda considera-se que o profissional possui competência por ter uma técnica altamente especializada, a excessiva especialização já é observada em várias profissões da área de saúde. ${ }^{14,18-20}$ Somente no ano de 2006 que a área de saúde coletiva tornou uma especialidade da Fonoaudiologia.

A formação de doutores implica no futuro da fonoaudiologia enquanto ciência, na sua autonomia gerando conhecimento por meio de pesquisas e na prática clínica fundamentando a sua atuação indo de encontro à demanda de serviços. ${ }^{21}$

A retrospectiva histórica da fonoaudiologia mostra uma atuação fortemente marcada pelos aspectos clínicos centralizados nas técnicas, com uma formação extremamente tecnicista levando a busca pela especialização, seguindo a tendência, a maior ênfase no processo curativo reparador aliada ao mercantilismo presente no movimento do capital, caracterizado pelo consumo privado de bens e serviços sob regulação do mercado, ou seja, é a demanda e exigência do mercado que regula a especialização e a inserção do profissional. ${ }^{20,22,23}$ 
Ao pensar no profissional generalista não é reduzir o entendimento de que a sua formação é deficiente e desqualificada e sim um profissional atuante com qualidade e resolubilidade, os docentes devem ser educadores e não especialistas, ou seja, o fonoaudiólogo clínico deve ser o profissional que atua preventivamente, participando das equipes inter e multidisciplinares e pratica o encaminhamento às especialidades requeridas. ${ }^{7,13,24,25}$

Observa-se que existe um predomínio das áreas de audição e linguagem, o que pode ser explicada pela demanda de mercado e pela tecnologia crescente em audiologia e pela detecção e tratamento de alterações da linguagem nas creches e primeiros anos de estudo. A precariedade e escassez de docentes com formação em saúde pública afastam cada vez mais os compromissos com o SUS e, por conseguinte com as equipes de saúde da família. No entanto, já é notado que em todas as IES estudadas grandes esforços e projetos estruturados e em funcionamento, como trabalhos com a comunidade, Pró-saúde, estão mobilizando docentes e discentes para voltarem suas ações para a promoção de saúde da coletividade.

Observa-se que as instituições públicas possuem mais docentes com titulação mais alta, pois é exigência e as IES privadas apenas cumprem a exigência mínima uma vez que acarreta em custos mais elevados. Nota-se o predomínio na pós-graduação de áreas correlatas, o que não seria necessário se pelo menos uma IES pública ofertasse a pós-graduação em fonoaudiologia, já que conta com a equipe docente necessária.

Muitos profissionais consideram que a realização de mestrado e doutorado é necessário somente para o exercício docente, esquecendo que o estudo junto com a prática é a melhor maneira de atualização profissional. ${ }^{10}$

O exercício profissional do docente supre ainda as necessidades individuais e privadas, sendo elitista e ligada ao mercado de trabalho privado. Mostra-se nessa relação que o aspecto de promoção da saúde e preventivo, seja de atenção primária ou secundária quase inexiste, pois o que se segue é a demanda privatista da atenção terciária. Observa-se que o número de docentes que atuam ligados a órgãos públicos é pequeno, o que compromete sobremaneira a participação do fonoaudiólogo no SUS, nas equipes de saúde da família, trazendo prejuízos relevantes à sociedade. ${ }^{16,22,26-30}$

Constata-se que é uma carga horária considerada alta se levar em consideração que além da atuação docente, atuam também, como profissionais. Deve-se levar em consideração que nas instituições públicas os docentes substitutos não fazem parte do quadro efetivo de docentes, não tendo, portanto estabilidade assim como os demais professores das IES privadas.

O plano de carreira nas IES públicas está iniciando, pois a gradação esta ocorrendo principalmente na federal, já na estadual esta acontecendo mais lentamente. Nas IES privadas o plano de carreira não está integralmente implantado ou é insuficiente, pois a maioria dos docentes são horistas. Outro motivo é que nas IES públicas a estabilidade financeira e os salários são maiores, já o que acontece nas IES privadas é um acúmulo de horas em várias IES por um mesmo docente para obter um melhor retorno financeiro.

As IES, ou seja, os empregadores deveriam ter e/ ou melhorarem suas políticas de educação continuada, pois o docente, também deveria ser um pesquisador e a educação e aprimoramento são essenciais para isso. Porém não foi citado o treinamento pedagógico específico voltado para o ensino superior, o mestrado e o doutorado são instrumentos de aprendizado e acúmulo de informações, porém, muitas vezes não é ensinada nesses cursos de pós-graduação a melhor maneira de repassar o conhecimento. O mestrado se destina a formar profissionais voltados para o exercício do magistério enquanto que o doutorado se destina à formação de pesquisadores.

Observa-se que, apesar de 32 docentes não concordarem com as DCN, a maioria (41 docentes) considera os conteúdos abordados e os procedimentos metodológicos suficientes para a formação profissional. Isso pode sugerir, talvez, uma acomodação na busca de melhores metodologias de ensino, de transpor o processo de ensino-aprendizagem para o discente e sua profissionalização, ou uma certa decepção com a administração das IES em que lecionam. Já 21 docentes concordam com as DCN e consideram que os conteúdos abordados e os procedimentos metodológicos não são suficientes para a formação do fonoaudiólogo; esses profissionais têm um posicionamento claro e buscam mudanças e adequações ao ensino. Esses dados sugerem uma contradição no entendimento dos docentes entrevistados, pois somente um projeto pedagógico e um currículo está em fase de observação e em início de implementação das novas DCN seguindo os princípios do SUS, enquanto os demais estão em fase de adequação e reforma curricular, com sinalizações de que esses conteúdos poderão ser revistos, ampliados, modificados e/ou atualizados e mais conhecidos pelos docentes.

Esses dados demonstram a tentativa de formar, durante a graduação, fonoaudiólogos generalistas e que se adequem às exigências do Ministério da Saúde e do SUS, em conformidade com as Novas 
Diretrizes Curriculares para o curso. ${ }^{1,12}$ As políticas públicas não primam pelo planejamento estratégico de longo prazo, o que dificulta a inserção do fonoaudiólogo nos serviços públicos de saúde. A partir de mudanças decorrentes das leis e diretrizes, espera-se um avanço, mesmo que incipiente, para a situação do profissional, ampliando-se, assim, o mercado de trabalho, uma vez que a demanda existe e é grande. ${ }^{15,26}$ Os profissionais que formam equipes de saúde devem ter uma educação continuada, o que possibilitaria a articulação entre eles e os saberes científicos, da saúde coletiva e da gestão pública a partir das necessidades locais. ${ }^{15}$

Observa-se um moderado percentual de docentes que se dedicam a ações preventivas, tanto os fonoaudiólogos quanto os de áreas correlatas, o que implica prejuízos para o SUS e para os programas de saúde pública. Tal situação sugere uma dificuldade a ser futuramente assimilada, com vistas à adaptação às exigências das diretrizes curriculares e dos Ministérios da Saúde e da Educação. Tal situação pode ser explicada pelo simples fato de que a maioria dos docentes obtiveram uma formação acadêmica anterior à instituição da saúde coletiva como área da Fonoaudiologia.

\section{CONCLUSÕES}

A formação acadêmico-profissional dos docentes fonoaudiólogos demonstrou ser, preferencialmente, tecnicista e especializada com prerrogativa dos saberes técnicos pertinentes à profissão e com limitado envolvimento em ações educativas preventivas e de atividades voltadas para os interesses do SUS, evidenciado pelo fato dessas ações ocorrerem apenas nas disciplinas específicas relacionadas à saúde coletiva.

A formação pedagógica adquirida pelos docentes em geral, resulta, na maioria das vezes, de iniciativa própria e (ou) como parte de cursos de pós-graduação realizados, o que tem evidenciado um longo caminho percorrido pelos mesmos para atender à formação docente requerida para o exercício pleno do magistério superior interdisciplinar.

Os docentes com formação em Fonoaudiologia expressaram relevante grau de envolvimento no processo de formação discente com vistas à qualidade do exercício profissional e à importância e valorização do fonoaudiólogo, demonstrando, seja de forma direta, por meio da conduta no exercício do magistério, seja de forma indireta, ao se referirem à própria história acadêmico-profissional.

Nota-se nas IES baianas que o perfil tecnicista docente não impossibilitou o grande avanço nas modificações dos parâmetros de formação focados nas questões preconizadas pelo SUS, com ações comunitárias e práticas em lócus diferenciados, e isso acontecendo dentro dos cursos em que o mais antigo em funcionamento completou onze anos.

\section{AGRADECIMENTOS}

Os autores agradecem o apoio recebido da Fundação de Amparo à Pesquisa do Estado da Bahia - Fapesb

\begin{abstract}
Purpose: to analyze the qualification of teaching staff in Speech and Language Pathology toward the design of academic and professional profile of the same. Method: data dealing with the qualification of the universe of Speech and Language Pathology teachers were collected through a questionnaire specifically designed for this purpose and treated based on descriptive statistics. Results: analysis showed the universe of 62 faculty members spread over four IES, mostly females and young, who had graduated in other states, and whose academic and professional training proved to be technical and specialized with the prerogative of technical knowledge being relevant to the profession. Conclusions: it is perceivable that, although with a qualification that mostly did not include the area of public health, teachers realize this need and seek, within the areas of performance, to set forth alliances with preventive actions.
\end{abstract}

KEYWORDS: Speech, Language and Hearing Sciences; Education; Professional Practice; Public Health 


\section{REFERÊNCIAS}

1. Brasil. Resolução CNE/CES 3/2002. Institui diretrizes curriculares nacionais do curso de graduação em Fonoaudiologia. Diário Oficial da União, Brasília, 04 mar. 2002.

2. Oliveira BSA, Margall SAC. Discussão clínica interdisciplinar como instrumento na formação do terapeuta: uma experiência em fonoaudiologia. Mundo Saúde. 2006; 30 (1): 160-5.

3. Santos PL, Rodrigues ML. O ensino da Psicologia na graduação de Fonoaudiologia. Medicina. 2007; 40 (1): 78-81.

4. Santos LAS, Silva MCM, Santos JM, Assunção MP, Portela ML, Soares MD et al. Projeto pedagógico do programa de graduação em Nutrição da Escola de Nutrição da Universidade Federal da Bahia: uma proposta em construção. Rev Nutr. 2005; 18 (1): 105-17.

5. Trenche MCB, Barzaghi L, Pupo AC. Mudança curricular: construção de um novo projeto pedagógico de formação na área da Fonoaudiologia. Interface. 2008; 12 (27): 697-711.

6. Mancopes R, Cutolo LRA, Tesch D, Schultz F, Santos RB; Mafatti $R$ et al. Interdisciplinaridade na fonoaudiologia: a concepção do professor. Rev CEFAC. 2009; 11 (2): 175-82.

7. Lazzarin HC, Nakama L, Cordoni Junior L. Percepção de professores de odontologia no processo de ensino-aprendizagem. Ciênc saúde coletiva. 2010; 15 (1): 1801-10.

8. Chieppe DC, Ferreira LP. A interlocução entre a fonoaudiologia e a docência. Distúrb Comum. 2007; 19 (2): 247-56.

9. Oliveira MHMA, Gargantini MBM. Universidade, formação e Fonoaudiologia. Pro-Posições. 2003; 14 (1): 39-51.

10. Goulart BNG, Chiari BM. Avaliação clínica fonoaudiológica, integralidade e humanização: perspectivas gerais e contribuições para reflexão. Rev Soc Bras Fonoaudiol. 2007; 12 (4): 335-40.

11. Haddad S. A educação continuada e as políticas públicas no Brasil. REVEJ@. 2007; 1: 27-38.

12. Brasil. Pró-saúde: programa nacional de reorientação da formação profissional em saúde / Ministério da Saúde, Ministério da Educação. (Série C. Projetos, Programas e Relatórios). Brasília: Ministério da Saúde, 2005. 77p. Disponível em: <http://www.abem-educmed.org.br/pro_saude/ publicacao_pro-saude.pdf>. Acesso em: 26 set. 2010.

13. Feuerwerker LCM. Educação dos profissionais de saúde hoje: problemas, desafios, perspectivas e as propostas do Ministério da Saúde. Rev ABENO. 2004; 3 (1): 24-7.
14. Mello SMF. Os cirurgiões-dentistas docentes dos cursos de Odontologia do Estado da Bahia, 2008-2009: estudo sobre formação e desempenho pedagógico. 2009. 183f. Dissertação (Mestrado) Faculdade de Odontologia da Universidade Federal da Bahia, Salvador, 2009.

15. Haddad AE, Pierantoni CR, Ristoff D, Xavier IM, Giolo J, Silva LB. (Org.). A trajetória dos cursos de graduação na área da saúde: 1991-2004. Brasília: Instituto Nacional de Estudos e Pesquisas Educacionais Anísio Teixeira, 2006. 15 v.

16. Moimaz SAS, Saliba NA, Blanco MRB. A força do trabalho feminino na odontologia, em Araçatuba - SP. J. Appl. Oral Sci. 2003; 11 (4): 301-5.

17. Cardoso C, Abreu TT. A fonoaudiologia na Bahia: uma história recente. Rev. Baiana de Saúde Publ. 2004; 28 (1): 96-9.

18. Ristoff D, Giolo J. (Org.). Educação superior brasileira 1991-2004. Brasília: Instituto Nacional de Estudos e Pesquisas Educacionais Anísio Teixeira, 2006. 28 v.

19. Brasil. Resumo Técnico. Censo da Educação Superior 2008 (Dados preliminares). Instituto Nacional de Estudos e Pesquisas Educacionais Anísio Teixeira. Brasília, DF, 2009.

20. Brasil. Instrumento de avaliação de cursos de graduação. Brasília: Instituto Nacional de Estudos e Pesquisas Educacionais Anísio Teixeira, 2006. $119 p$.

21. Andrade CRF. Editorial. Pró-Fono R. Atual. Cient. 2009; 21 (2): 89-94.

22. Secco LG, Pereira MLT. Concepções de qualidade de ensino dos coordenadores de graduação: uma análise dos cursos de odontologia do Estado de São Paulo. Interface. 2004; 8 (15): 313-30.

23. Pizzatto E, Garbin CAS, Garbin AJÍ, Saliba NA et al. O papel do professor no ensino odontológico / The role of the professor in dental education. Saúde em Debate. 2004; 28 (66): 52-7.

24. Kriger L. O diferente é formar o generalista. Rev. de Clín. Pesq. Odontol.Editorial. 2005; 1 (4): 7-9.

25. Penteado RZ, Servilha EAM. Fonoaudiologia em Saúde Pública/ Coletiva: compreendendo prevenção e o paradigma da prevenção em saúde. Distúrb Comun. 2004; 16 (1): 107-16.

26. Nunes RTD'A. Fonoaudiologia e memória: narrativas sobre 0 início das práticas fonoaudiológicas na cidade de Salvador. 2007. $199 f$. Dissertação (Mestrado) - Pontifícia Universidade Católica de São Paulo, São Paulo.

27. Silva SLB, Musse RIP, Nemr K. Assistência domiciliar na Cidade de Salvador-BA: possibilidade de atuação fonoaudiológica em motricidade orofacial. Rev CEFAC. 2009; 11 (1): 94-101. 
28. Ferreira RC, Fiorini VML, Crivelaro E. Formação profissional no SUS: o papel da Atenção Básica em Saúde na perspectiva docente. Rev Bras Educ Med. 2010; 34 (2): 207-15.

29. Bazzo LM. Informação em saúde: subsídios para caracterização da oferta de serviços fonoaudiológicos no Sistema Único de Saúde
(SUS) em Salvador. Rev Ciênc Med Biol. 2007; 6 (2): 214-6.

30. Bazzo LM, Noronha CV. A ótica dos usuários sobre a oferta do atendimento fonoaudiológico no Sistema Único de Saúde (SUS) em Salvador. Ciênc saúde coletiva.2009; 14 (5): 1553-63.

Endereço para correspondência:

Vanessa De Nardi

Av. Gal. Severino Filho, 750, al. Sereia, 57

Cond. Pedra do Sal Residências, Itapuã

Salvador - BA

CEP: 41635-540

E-mail: vanessadenardi@ig.com.br 